\title{
BIBLIOMETRIA E METASSÍNTESE DE ESTUDOS SOBRE TRABALHO PUBLICADOS NA REVISTA PSICOLOGIA \& SOCIEDADE
}

\author{
BIBLIOMETRÍA Y METASÍNTESIS DE LOS ESTUDIOS SOBRE EL \\ TRABAJO PUBLICADO EN LA REVISTA PSICOLOGIA \& SOCIEDADE \\ BIBLIOMETRICS AND METASYNTHESIS OF STUDIES ON WORK \\ PUBLISHED IN THE JOURNAL PSICOLOGIA \& SOCIEDADE
}

http://dx.doi.org/10.1590/1807-03102016v28n3p572

Adélia Augusta Souto de Oliveira, Cristina Generino dos Santos Lima

e Kalina Karla Clemente de Morais

Universidade Federal de Alagoas, Maceió/AL, Brasil

\section{RESUMO}

Este artigo apresenta uma análise descritiva e exploratória sobre as publicações do periódico online Psicologia \& Sociedade, que abordam a categoria 'trabalho' como objeto de estudo. Foi realizada em quatro etapas, sendo a primeira bibliométrica: quantificação da produção da revista no quinquênio 2010-2014, em todas as suas categorias de publicações. As fases posteriores corresponderam à metassíntese dos títulos e resumos dos artigos, com recorte especial no método de cada produção. Por último, dois artigos provenientes de pesquisas teóricas foram analisados, de modo a subsidiar uma crítica interna à produção científica. Os resultados demonstraram que a revista tem expressiva produção no campo da Psicologia do Trabalho, sendo esta uma categoria fundamental para a compreensão histórica e cultural da subjetividade e dos processos de saúde e adoecimento, como também, asseveraram acerca da qualidade das publicações, concretizando a proposta do periódico em estabelecer um diálogo constante da ciência psicológica com a sociedade.

Palavras-chave: trabalho; psicologia do trabalho; Psicologia \& Sociedade.

\section{RESUMEN}

Este artículo presenta un análisis descriptivo y exploratorio de las publicaciones de la revista Psicologia \& Sociedade, que se refieren a la categoría 'Trabajo' como objeto de estudio. Se llevó a cabo en cuatro etapas, la primera bibliométrico: cuantificación de la producción de la revista en el período de cinco años, 2010-2014, en todas sus categorías de publicaciones. Las fases posteriores correspondieron a metasíntesis de los títulos y resúmenes de los artículos, con recorte especial en el método de cada producción. Por último, dos artículos de investigación teórica se analizaron con el fin de apoyar una crítica interna de la literatura científica. Los resultados mostraron que la revista tiene una producción significativa en el campo de la Psicología del Trabajo, siendo esta como una categoría fundamental para la comprensión histórica y cultural de la subjetividad y de los procesos de salud y enfermedad, y afirmaran la calidad de las publicaciones.

Palabras clave: trabajo; psicología del trabajo; Psicologia \& Sociedade.

\begin{abstract}
This article presents a descriptive and exploratory analysis of the publications of the online journal Psicologia \& Sociedade, which addresses the 'Work' as an object of study. Such analysis was performed in four steps, being the first bibliometric: quantification of magazine production in the five-year period 2010-2014, in all its categories of publications. Later phases of the analysis corresponded to metasynthesis the titles and abstracts of articles with special cutout in each method of production. Finally, two articles from theoretical research were analyzed in order to support an internal critique of the scientific literature found in the journal. The results showed that the magazine has significant production for Occupational Psychology, this as a fundamental category for the historical and cultural understanding of subjectivity and the processes from health and illness. It has also assured the quality of publications, implementing the proposal of the journal which is to establish a constant dialogue of science psychological society.
\end{abstract}

Keywords: work; occupational psychology; Psicologia \& Sociedade. 


\section{Introdução}

Há indícios de que a Psicologia do Trabalho, campo de conhecimento e intervenção em interface com a Psicologia do Trabalho e das Organizações, no Brasil, acompanha a própria história da psicologia no país, desde o início do século XX, antes mesmo da regulamentação da profissão, sendo historicamente marcado por numerosas polêmicas de cunho ideológico e teórico-metodológico, que se estendem na atualidade. Isso porque, a Psicologia do Trabalho, por vezes, parece representar compromisso com setores ideologicamente conservadores e com a manutenção do status quo, pondo em questionamento, sobretudo, a serviço de quem está esse campo do saber e sobre qual seria o seu objeto principal (Borges, 2010).

É comum encontrar relação da Psicologia do Trabalho e das Organizações com teorias comportamentais e da aprendizagem que focam em sistemas de classificação, desenvolvimento de competências, análise de desempenho, recrutamento e seleção, etc. Contudo, a ampliação do olhar de pesquisadores sobre tal campo tem incorporado novas práticas e modos de compreendê-lo, especialmente no que tange ao 'Trabalho' e à Saúde do Trabalhador.

Deste modo, a categoria 'Trabalho' foi escolhida por possuir relevância social e científica, pois suscita uma discussão crucial para a Ciência Psicológica. Apresenta, assim, a proposta de superar paradigmas cristalizados e auxiliar numa reconstrução sobre o entendimento do que vem a ser o 'Trabalho'. Essa reflexão se pauta na perspectiva em que o saber fazer dos trabalhadores configura-se como categoria central para a compreensão da subjetividade dos indivíduos e dos processos de saúde e adoecimento (Dejours, 1987).

$\mathrm{O}$ presente artigo se trata de um estudo bibliográfico, realizado a partir de uma análise descritiva e exploratória, referente às publicações da revista online Psicologia \& Sociedade, que abordam o 'trabalho' como objeto de pesquisa.

O periódico em estudo foi criado pela ABRAPSO - Associação Brasileira de Psicologia Social - em 1986, e publica anualmente três números, podendo lançar mais uma ou duas edições especiais. Tem como proposta divulgar artigos inéditos a respeito de temas que privilegiam produções que fazem interface da psicologia com a sociedade, a fim de promover uma Psicologia Social numa perspectiva crítica, transformadora e interdisciplinar.

O delineamento do tempo utilizado para o levantamento de dados da revista, de 2010 a 2014 , foi uma estratégia de conhecer e compartilhar com a comunidade científica o que vem sendo discutido nos últimos anos, de forma também a nortear a construção de novos saberes.

Sendo assim, este estudo foi dividido em quatro etapas, uma quantitativa - bibliometria - e três qualitativas - metassíntese de títulos, resumos e artigos, de modo que nos subsidiou a fazer uma crítica interna à produção científica encontrada no periódico online Psicologia \& Sociedade, concernente ao período analisado e segundo a categoria escolhida.

A bibliometria é um tipo de pesquisa bibliográfica, proveniente da Ciência da Informação, que consiste numa técnica quantitativa e estatística. Permite, ainda, uma análise qualitativa quando, por meio de um mapeamento da literatura publicada, tem-se um panorama sistemático que facilita a apropriação, por parte do pesquisador, acerca do que já foi elaborado sobre determinada temática, teoria, método ou a partir de um banco de dados, que servirá de parâmetro para atestar a relevância científica de uma nova pesquisa (Araújo, 2006).

Já a etapa qualitativa foi contemplada através de uma metassíntese de títulos, resumos e artigos com enfoque no método. Esse tipo de pesquisa, de acordo com Matheus (2009), constitui-se num método de análise de dados, cuja síntese interpretativa geralmente sucede a etapa quantitativa de um estudo. Objetiva, desta maneira, fortalecer e melhorar a aplicabilidade dos resultados, bem como subsidiar a fundamentação de novas teorias, práticas e pesquisas.

Na metassíntese de títulos, houve dois recortes: o primeiro temático, realizado para compor o banco de dados inicial; e o segundo, com enfoque no método. $\mathrm{Na}$ efetivação da análise dos resumos, mantémse o método como foco de escolha, tendo em vista sua tipificação. Quanto ao método, é indispensável enfatizar que, conforme Furlan (2008, p. 25): “é sempre um caminho provisório para responder a determinada questão, e a pesquisa, percorrendo-o, pode suscitar outras questões, revelar becos sem saídas aparentes, sugerir novas direções ou ideias".

Concomitante a isso, fizemos uma análise qualitativa dos artigos. Para tanto, recorremos à seleção de dois deles por se tratar de pesquisa do tipo teórica, com o intuito de aprofundar o estudo com base nas teorias que versam acerca do trabalho e dialogam com a psicologia. Logo, auxiliar na construção argumentativa para pensarmos a Psicologia do Trabalho a partir de referenciais que versam sobre ela. Nessa direção, corrobora-se que "a 
pesquisa teórica não implica imediata intervenção na realidade, mas nem por isso deixa de ser importante, pois seu papel é decisivo na criação de condições para a intervenção" (Demo, 1994, p. 36).

\section{Metodologia}

As estratégias utilizadas se deram em quatro etapas: a primeira resumiu-se num levantamento estatístico das produções (bibliometria), a partir das onze categorias utilizadas pela revista para a publicação de estudos científicos: Editorial, Ensaios Teóricos, Resenhas, Entrevistas, Traduções, Convite ao debate, Relação de consultores, Notícias Abrapso, Homenagens, Prêmio Abrapso e Artigos, estes que podem apresentar revisões críticas de literatura, estudos teóricos e relatos de pesquisa. Os dados que compunham os índices das referidas produções científicas, entre os anos de 2010 a 2014, foram obtidos do acervo online da própria revista.

Como instrumento norteador desta primeira etapa, valemo-nos do seguinte roteiro: Tabulação de quantitativo de publicações por ano, volume e número da revista, especificadas através das onze categorias já mencionadas; Construção de quadros, tabelas e gráficos; Apresentação e interpretação dos dados; Discussão dos resultados.

$\mathrm{Na}$ segunda etapa, que correspondeu à metassíntese de títulos, dentre todas as categorias publicadas pela revista Psicologia \& Sociedade, selecionamos a modalidade Artigo (revisões críticas de literatura, estudos teóricos e relatos de pesquisa), por possuir maior número de publicações, no quantitativo de 425 (Tabela 1). Essa construção qualitativa pretende proporcionar uma compreensão ampla, ao primeiro contato com as produções, sobre a categoria 'Trabalho', com ênfase aos títulos que destacavam o método.

Com base nos resultados obtidos na etapa bibliométrica, utilizamos um roteiro com as seguintes fases: Tabulação - construção de quadro, contendo os 425 títulos dos artigos publicados; Refinamento - os critérios de recorte de títulos utilizados foram: apresentar o descritor 'Trabalho' e/ou palavras que contivessem o radical deste descritor, ou seja, 'Trabalh' e/ou apresentar títulos com objetos de pesquisa convergentes a tal temática; Construção de quadros e tabelas; Apresentação e interpretação dos

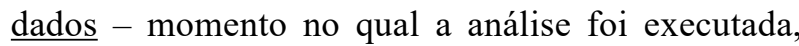
título a título, de modo a classificá-los nas seguintes categorias acerca das propostas que apresentaram: tema, teoria, método, resultados. A partir desta fase, nosso enfoque foi direcionado para o método usado em pesquisas que discutiam a categoria 'Trabalho'; Discussão dos resultados.

A terceira fase consistiu na metassíntese de resumos, com ênfase no método, a qual resultou num quantitativo de 15 artigos. Com o propósito de sistematizar esta etapa qualitativa, constituiu-se um roteiro com as seguintes fases: Leitura dos resumos usou-se como critério de descarte a não conformidade com a categoria escolhida; Categorização - avaliou-se se os resumos apresentavam todos os itens necessários - objeto de pesquisa, objetivos, metodologia e resultados. Ainda que algum resumo não apresentasse um ou mais itens, não foi delimitado critério de exclusão. Todos os artigos foram considerados para a fase seguinte: Tipificação do Método - Visou destacar e discutir o tipo de método que vem sendo utilizado nos estudos com a categoria 'Trabalho', de maneira a balizar pesquisas futuras nessa área do conhecimento.

Por último, foram analisadas as produções dos 15 artigos. Destes, foram escolhidos dois, classificados como pesquisas teóricas, ambos publicados no ano de 2013. Tais estudos tiveram como campo de conhecimento outros textos que versam a respeito da categoria de análise 'Trabalho' articulada com perspectivas teóricas diferentes, mas complementares. "Para classificar os documentos em relação aos fundamentos, verificou-se se definiam teoria, buscando identificar a teoria sobre a qual o autor diz que construiu sua análise" (Trancoso, 2012, p. 57). Após leitura integral, os artigos foram apresentados no capítulo Discussões, sendo exibidos os principais argumentos teóricos e autores de referência.

\section{Resultados}

A bibliometria realizada permite mostrar a tabulação do quantitativo de publicações por ano, volume e número da revista, especificadas através das onze categorias utilizadas para a publicação de trabalhos científicos pela revista Psicologia \& Sociedade, sintetizadas na Tabela 1.

Foi possível observar que, nos últimos cinco anos, o periódico publicou 498 trabalhos, de modo crescente. Constatou-se que, de 2010 a 2014, não houve nenhuma publicação na categoria Ensaios teóricos. Os itens Homenagem, Relação de consultores, Convite ao debate, Traduções e Entrevistas somaram poucas publicações, havendo apenas de uma a três em todo o período analisado. 
Tabela 1. Resumo geral de publicações de 2010 a 2014

\begin{tabular}{|c|c|c|c|c|c|c|}
\hline \multicolumn{6}{|c|}{ REVISTA PSICOLOGIA \& SOCIEDADE } & \multirow[b]{2}{*}{ Total dos últimos 5 anos } \\
\hline Categorias de Publicação/Ano & 2010 & 2011 & 2012 & 2013 & 2014 & \\
\hline $\begin{array}{l}\text { Artigos: } \\
\text { - Revisões críticas de literatura } \\
\text { - Estudos Teóricos } \\
\text { - Relatos de Pesquisa }\end{array}$ & 59 & 81 & 87 & 96 & 102 & 425 \\
\hline Resenhas & 4 & 6 & 6 & 5 & 4 & 25 \\
\hline Editorial & 3 & 4 & 4 & 5 & 5 & 21 \\
\hline Prêmio Abrapso & 0 & 0 & 0 & 0 & 9 & 9 \\
\hline Notícias Abrapso & 3 & 3 & 0 & 0 & 0 & 6 \\
\hline Entrevistas & 2 & 0 & 0 & 1 & 0 & 3 \\
\hline Traduções & 1 & 0 & 0 & 1 & 1 & 3 \\
\hline Convite ao Debate & 1 & 0 & 1 & 1 & 0 & 3 \\
\hline Relação de Consultores & 0 & 1 & 1 & 0 & 0 & 2 \\
\hline Homenagem & 0 & 1 & 0 & 0 & 0 & 1 \\
\hline Ensaios Teóricos & 0 & 0 & 0 & 0 & 0 & 0 \\
\hline Total de Publicações/ ano & 73 & 96 & 99 & 109 & 121 & 498 \\
\hline
\end{tabular}

Fonte: Autoras (2016)

Em contrapartida, percebe-se que as quatro categorias em que há mais publicações, no último quinquênio, são, respectivamente: Artigos (425), Resenhas (25), Editorial (21) e Prêmio Abrapso (9), conforme aponta a Tabela 1. Todavia, vale salientar que esta última categoria foi encontrada em apenas um único número do periódico, sendo este especial.

Dentre as categorias mais publicadas, é possível confirmar que, em cinco anos, a categoria Artigo apresentou aumento progressivo. As publicações nessa modalidade tiveram os seguintes aumentos, aproximadamente: de 2010 para 2011, 37\%; entre 2011 e 2012, 7\%; 10\%, de 2012 para 2013; e 6\%, entre 2013 e 2014. Se compararmos a quantidade de publicações de Artigos em 2010 e 2014, notaremos um aumento representativo de $72 \%$. Além disso, também a partir da Tabela 1, pode-se inferir que a revista Psicologia \& Sociedade mostrou um aumento expressivo de publicações, considerando que, em 2010, publicou 73 manuscritos e, em 2014, 121, ou seja, aproximadamente $66 \%$, em apenas cinco anos.

A análise de títulos a partir do critério de presença da categoria 'Trabalho', por ano, permitiu afirmar um número considerável de artigos publicados sobre essa categoria, nos últimos cinco anos, totalizando 38; sendo que, em 2010, as produções somaram apenas quatro, um número ainda incipiente, se considerada a crescente produção nos anos posteriores. Adiante, precisamente no ano de 2011, as publicações excederam a duplicação do total anterior, havendo nove estudos; muito embora se tenha percebido um decréscimo no ano sucessor, 2012, com cinco.

Por outro lado, os anos de 2013 e 2014 superaram a quantidade de publicações com a categoria 'Trabalho', abarcando 09 e 11 publicações, respectivamente. Desta forma, o periódico Psicologia \& Sociedade tem demonstrado expressiva contribuição neste campo, tornando-se um banco de dados congruente com aquilo que se propõe a fazer, dada a complexidade de sua proposta, a saber: a construção de uma interface entre a ciência psicológica e a sociedade; considerando o 'Trabalho' como categoria de análise imprescindível na vida social e produtor de subjetividades.

Nesta segunda etapa de análise dos títulos dos artigos, para a Apresentação e interpretação dos dados, foi efetuada uma categorização dos 38 títulos dessas produções, em modalidades distintas: tema, teoria, método e resultados; a fim de empreendermos uma exploração significativa do material estudado, para então extrair de tal conteúdo apenas os títulos que enfatizam o método. 
Como resultado desta fase, a partir do refinamento categorial realizado, dos 38 títulos que compunham este banco de dados inicial, que diziam respeito àqueles que traziam a temática 'Trabalho' ou objetos de pesquisa com ela convergentes, resultaram 15 títulos, distribuídos da seguinte forma: oito referentes ao ano de 2014, cinco ao ano de 2013 e dois publicados em 2010 .

Nos títulos de 2014, evidenciamos, porém, alguns que aparecem com direcionamentos a outras categorias, como em: A narrativa como proposta metodológica para o estudo do Burnout (DutraThomé, Alencastro, \& Koller, 2014), quando literalmente a palavra 'metodológica' é usada como artifício para expressar a proposta dos escritos. Assinalamos, também, que a palavra 'Trabalho' não apareceu nesse título, mas, por inferência, o artigo foi selecionado, tendo em vista o conhecimento da 'Síndrome de Burnout', a qual se relaciona ao contexto do 'Trabalho'.

Outros títulos também merecem ser citados, como: Idosos aposentados no mercado de trabalho informal: trajetórias ocupacionais na construção civil (Cockell, 2014). Nesse caso, enfocamos o termo 'trajetórias' para aludir ao possível método utilizado no artigo. Vale ressaltar que tais construções constituem hipóteses para a compreensão desses títulos, uma vez que a análise dos resumos, terceira etapa desta pesquisa, consolidou tais informações.

Dando prosseguimento, o título Psicologia e trabalho docente: intercessões com a clínica da atividade (Barros, Passos, \& Eirado, 2014) apresenta um enfoque temático (Psicologia e trabalho docente), metodológico (intercessões), ofertando ao leitor uma ideia de um modo de fazer a partir da correlação; e teórico, quando se propõe a pensar a Clínica da Atividade, por meio da qual alguns autores da Psicologia do Trabalho dialogam.

Por outro lado, os artigos intitulados: Representações sociais acerca do trabalho e moradia: o caso da Vila Chocolatão (Dias, Cherfên, Raupp, \& Milnitisky-Sapiro, 2014); Saberes sobre o trabalho: experiência e história nos canaviais (Silva \& Barros, 2014); Trabalhadores com deficiência: vivências de prazer e sofrimento (Coelho, Sampaio, \& Mancini, 2014); Trajetórias identitárias e sentidos do trabalho docente para professores universitários (Raitz \& Silva, 2014); Valores do trabalho e incubação de empreendimentos solidários: a experiência da associação Terra do Marolo (Carvalho, Villas Boas, Guerra, \& Freitas, 2014), sob a nossa interpretação, são todos temáticos e metodológicos.
Com relação aos títulos de 2013, também foram categorizados no quesito método: Implicações do trabalho precoce para adultos: vivências e infância (Santos, Alberto, Costa, \& Santos, 2013); Histórias de vida marcadas por humilhação, assédio moral e adoecimento no trabalho (Schlindwein, 2013); Uma abordagem metodológica para trabalhar com famílias no SUAS: uma leitura crítica através das lentes da cidadania (Afonso, Hennon, Carico, \& Peterson, 2013), sendo este último também classificado hipoteticamente como teórico, ainda que apenas o termo: 'lentes da cidadania' não garanta um aporte desse tipo; no entanto oferece margem para a utilização de alguma teoria na abordagem ao tema.

Em Relações antagônicas entre sentido e significado do trabalho no capital: uma análise na perspectiva ontológica (Gonçalves \& Jimenez, 2013), percebemos teoria e método ao alcance do leitor; e em Slow Movement: trabalho e experimentação do tempo na vida líquido-moderna (Batista, Grisci, Gallon, \& Figueiredo, 2013); a possibilidade de um título, além de temático, também metodológico. Referentes aos anos de 2011 e 2012 foram encontrados, a nosso ver, apenas títulos temáticos.

No ano de 2010, aparecem dois títulos com enfoque temático-metodológico: Stress ocupacional no ensino: um estudo com professores do $3^{\circ}$ ciclo e ensino secundário (Gomes, Montenegro, Peixoto, \& Peixoto, 2010) faz referência ao método, ainda que a palavra 'Trabalho' não apareça, o termo 'Stress ocupacional' torna-se um derivativo. Em Trajetórias de jovens no mundo do trabalho a partir da primeira inserção: o caso de Sísifo em Maracanaú - Ceará, Brasil (Rocha \& Góis, 2010), os vocábulos 'trajetórias' e ‘caso' também fazem menção ao método.

Segundo análise dos títulos, podemos inferir que aproximadamente 39\% daqueles encontrados na revista Psicologia \& Sociedade, que abordavam a categoria 'Trabalho', trataram-se de títulos metodológicos ou temático-metodológicos, totalizando o quantitativo de 15. Os demais títulos, 23 restantes, caracterizaram-se por serem predominantemente temáticos, havendo apenas dois que também contemplavam aspectos teóricos, e três que faziam menção aos resultados da pesquisa.

Além disso, foi possível observar que os estudos - realizados na perspectiva da categoria 'Trabalho' - que indicaram no título o método utilizado, quadruplicaram em 2014 com relação ao ano de 2010. Contudo, verificou-se que não houve pesquisas com o enfoque metodológico nos anos de 2011 e 2012, ou os pesquisadores optaram por não destacar a metodologia utilizada no título de seus trabalhos. 
$\mathrm{Na}$ análise de resumos, na fase de Leitura dos resumos, composta inicialmente pelo quantitativo de 15 artigos, descartaram-se três deles: um do ano de 2010, Stress ocupacional no ensino: um estudo com professores do $3^{\circ}$ ciclo e ensino secundário (Gomes et al., 2010), por identificar que o resumo não dava ênfase à categoria 'Trabalho'; e dois de 2014 descartados pelo mesmo motivo: A narrativa como proposta metodológica para o estudo do Burnout (Dutra-Thomé et al., 2014); e Saberes sobre o trabalho: experiência e história nos canaviais (Silva \& Barros, 2014).

Deste modo, resultaram 12 artigos que seguiram para a fase de Categorização. Todos os itens que devem conter num resumo, a dizer, objeto de pesquisa, objetivos, metodologia e resultados, definidos nesta pesquisa como categorias, foram contemplados nos 12 artigos analisados. Seguimos para a próxima fase com a mesma quantidade de títulos, a fim de realizar uma Tipificação do Método.

$\mathrm{Na}$ análise dos métodos utilizados nos 12 artigos do banco de dados, que abordaram a categoria 'Trabalho', ou afins, e que apresentaram títulos metodológicos ou temático-metodológicos, observouse que, de 2010 a 2014, todos os estudos com essas características tiveram caráter qualitativo. Reiteramos que nos anos de 2011 e 2012 não obtivemos produções cujos títulos enfatizassem a metodologia.

Ademais, dos 12 artigos analisados, a maioria tratou-se de pesquisas de campo, correspondendo ao quantitativo de cinco. Como recursos metodológicos, esses estudos se valeram, em sua maioria, de entrevistas semiestruturadas; tendo apenas um recorrido ao uso de entrevista aberta e outro ao grupo focal. Ainda, foram registradas duas pesquisas-intervenção, uma que teve como instrumento a autoconfrontação cruzada com fotos e vídeos; e outra que utilizou grupos terapêuticos e relatos de vivências como fonte de informações.

As duas pesquisas teóricas, que seguiram para análise completa de artigos, são de 2013: Relações antagônicas entre sentido e significado do trabalho no capital: uma análise na perspectiva ontológica (Gonçalves \& Jimenez, 2013); Slow Movement: trabalho e experimentação do tempo na vida líquidomoderna (Batista et al., 2013). Notou-se que a primeira, após a leitura dos resumos, mantém a convergência entre os vocábulos que fizeram referência ao método no título; e a segunda mostrou um distanciamento dessa categoria, quando se constatou que o termo 'experimentação', descrito no título, não corresponde a um caminho de análise na pesquisa, mas a uma maneira de "experimentar o tempo" na contemporaneidade. Entretanto, o referido artigo destaca, no resumo, que se trata de uma pesquisa teórica, congruente com a proposta de metassíntese dos artigos.

As tipologias de método das três pesquisas restantes foram: etnografia, com diário de campo e entrevistas; análise de documento de uma política pública; e um estudo de caso, com entrevista orientada. Observa-se, no resumo, a fidelidade ao método apresentado nos títulos.

Diante disso, seguimos para a discussão sobre relevantes referências no vasto universo da Psicologia do Trabalho, e não menos, sobre grandes contribuições que permeiam essa área do conhecimento. Acordado isso, elegemos também cinco categorias a fim de explorar o conteúdo dos dois artigos analisados na íntegra: Síntese do artigo, Principais Argumentos Teóricos, Aproximações entres eles, Contrastes e Teóricos utilizados.

\section{Discussões}

A bibliometria realizada neste estudo permite afirmar que a revista Psicologia \& Sociedade apresentou um aumento bastante significativo no número de estudos publicados; isso é expresso, sobretudo, pelo aumento de publicações das edições especiais do periódico online, que, a partir de 2013, passaram de um número para dois.

Tal ascensão expressiva demonstra também que a comunidade científica tem se engajado na construção de novos saberes, através da pesquisa e de sua veiculação, de modo a contribuir com a sociedade. Portanto, os resultados apresentados denotam potencialidade para investigar, pensar, discutir, entender e propor estratégias a fenômenos diversos.

Por outro lado, o estudo indica que algumas modalidades de publicação foram pequenas: Homenagem, Relação de consultores, Convite ao debate, Traduções e Entrevistas. Ao contrário, a modalidade de Artigos é a mais utilizada por pesquisadores para a veiculação dos seus trabalhos, simbolizando $86 \%$ dos manuscritos exibidos pela Revista, nos últimos cinco anos, enquanto que a soma das demais categorias expressa apenas $14 \%$ das publicações.

No periódico online Psicologia \& Sociedade, os títulos sobre a categoria 'Trabalho' foram considerados bastante representativos. Num total de 38 , a classificação utilizada permitiu identificar títulos temáticos, teóricos e metodológicos; sendo que a maioria deles se apresentou apenas como temáticos; outros como temáticos e metodológicos; e, ainda, 
temáticos e que aludem ao resultado; ou apresentando mais de duas categorias, incluindo a teoria. As nossas opções de classificação, escolha e interpretação foram construções que exigiram leitura cuidadosa e inferências que culminaram em tessitura de argumentações. Seja temático, teórico, metodológico ou que comporte resultados, os termos de um título precisam ser relevantes, concisos e coerentes.

Nessa direção, corrobora-se com a importância da clareza de todas as partes do texto científico, uma vez que pretendem comunicar sistematicamente as etapas da produção de determinado conhecimento. Além do que, a escolha do título varia conforme o enfoque atribuído pelo pesquisador a sua pesquisa, não havendo necessariamente uma prescrição engessada com tal finalidade.

Quanto à análise dos resumos, as categorias empreendidas foram: objeto de pesquisa, objetivos, metodologia e resultados, pontos cruciais para a elaboração de resumos em artigos científicos. De fato, a leitura deles foi indispensável para o avanço das análises subsequentes, visto que os títulos, por vezes, dificultaram a identificação de meandros da pesquisa, sendo necessário recorrermos a inferências, e com o prosseguimento do estudo, comprová-las ou não.

Para exemplificar tal proposição, selecionamos dois artigos, caracterizados nessa fase como pesquisas teóricas, publicados em 2013, e os únicos com essa tipologia, os quais foram trazidos à análise (na íntegra), de acordo com as cinco categorias estabelecidas, tornando-se mais um recorte da pesquisa. São eles: Relações antagônicas entre sentido e significado do trabalho no capital: uma análise na perspectiva ontológica (Gonçalves \& Jimenez, 2013) e Slow Movement: trabalho e experimentação do tempo na vida líquido-moderna (Batista et al., 2013). Esses priorizaram referenciais teóricos e permitiram aproximações e contrastes acerca da categoria 'Trabalho'. Para fins didáticos, serão apresentados, daqui em diante, o primeiro como Artigo A e o segundo, Artigo B.

O título do Artigo B foi classificado como metodológico, todavia, após a leitura dos resumos, percebeu-se que este mostrou um distanciamento dessa categoria, pois o vocábulo 'experimentação', no título, não corresponde a um método de análise na pesquisa, mas a uma forma de "experimentar o tempo" na pósmodernidade. O seu resumo indicou que se tratava de um estudo teórico.

Até aqui, chegamos mediante uma aproximação com o método; no entanto, incorremos agora a refletir sobre arcabouços teóricos no que diz respeito à problemática do 'Trabalho', e o que a ela puder se relacionar, diante desse vasto campo da Ciência Psicológica.

Por fim, a análise de ambos os artigos faz, alicerçados por construções diferentes acerca da categoria 'Trabalho', como também fundamentados em teóricos distintos, uma crítica ao sistema capitalista, com o fim de apresentar uma discussão endereçada à relação entre trabalho e capital. O primeiro artigo, Artigo A, apresentou-se, diante da nossa interpretação, categoricamente como um severo crítico ao sistema capitalista, relacionando teóricos importantes como Karl Marx, Friedrich Engels, Alexander Luria, Georges Lukács, Alexei Leontiev, dentre outros. Os referidos autores, articulados perante uma ontologia do ser social, serviram de suporte para a defesa de ideias marxistas sobre 'Trabalho', quando se apreende o constructo a respeito da consciência de classes.

A forma como os humanos se relacionam, no sistema capitalista, por meio da produção de bens, os torna alienados de sua própria existência, e essa transformação sofrida na estrutura interna da consciência ocorre a partir da divisão social do 'Trabalho'. Nesse contexto, a alienação constrói a formação do homem e as condições concretas de vida, que o descaracterizam como ser livre e consciente.

No Artigo A, as autoras também assinalam, na interlocução com os teóricos supracitados, que é possível a superação da sociedade do capital, através da consciência do ser social, partindo para uma revolução, tal como tantas têm se mostrado efetivas no curso da história da humanidade. Esse fato também é marcado pelas formações acadêmicas de cada uma delas, quando averiguamos que ambas possuem formação na área de Humanas, com foco social, voltadas para a Educação e Psicologia.

Por outro lado, o Artigo B discute os malefícios engendrados na sociedade capitalista, a degradação das relações e os tempos fluidos próprios da pósmodernidade. Constrói, assim, um arcabouço teóricocrítico do sistema capitalista, porém não subversivo diante dele.

O segundo artigo descreve o fenômeno cultural Slow Movement e seus derivativos para expressar uma "saída" às relações efêmeras e fluídas dos tempos atuais, de igual modo, transformadas em alienantes em razão do capitalismo. Assim, a categoria 'Trabalho' aparece como produtora de subjetividades. Segundo Dejours (1987):

A organização do trabalho exerce sobre o homem uma ação específica, cujo impacto é o aparelho psíquico. Em certas condições emerge um sofrimento que pode 
ser atribuído ao choque entre uma história individual, portadora de projetos, de esperanças e de desejos e uma organização do trabalho que o ignora. (p. 50)

É importante lembrar que, no final da década de 1970, o olhar voltado aos trabalhadores começa a ser redefinido, a partir dos movimentos sociais, em especial os sindicais, e da Reforma Sanitária brasileira e, com isso, também se amplia a compreensão da categoria 'Trabalho'. A Saúde Coletiva redimensiona o entendimento sobre os processos de trabalho, considerando-o em suas diferentes formas de organização, divisão e valorização, bem como as relações históricas e sociais de sua produção, para além das questões ambientais. Toma, portanto, o sujeito, enquanto ser social e político, capaz de transformar sua realidade de trabalho, buscando compreender as mediações entre trabalho e subjetividade (Sato, Lacaz, $\&$ Bernardo, 2006).

O Slow Movement, conceito apresentado no Artigo B, mostra-se como uma tentativa de apaziguar as fracas relações ocasionadas pelo sistema; uma forma de cuidado com o tempo e os vínculos que construímos durante a vida, com o intuito de desacelerar a corrida empreendida pelo lucro e sucesso tão estimados em nossos tempos líquidos. Teóricos como Zygmunt Bauman e Jacques Christophe Dejours foram essenciais para a compreensão do Slow Movement; contudo, os autores do referido artigo ressaltam que esse fenômeno é tido como uma filosofia de vida adotada em alguns lugares, mas não se constitui como uma consciência do ser social, propulsora de revoluções, tendo em vista a necessidade de transformações sociais.

As autoras do Artigo B realizaram seu percurso acadêmico em Administração e apropriaram-se de alguns teóricos de áreas como Filosofia, Sociologia e Psicologia, fato que demonstra como a categoria 'Trabalho' tem se expandido e alcançado mudanças consideráveis. Deste modo, possibilita reflexões sobre os sentidos a ele atribuídos e as implicações disso no contexto contemporâneo, como os processos identitários, cuja constituição ocorre por meio da dialética relação homem-sociedade.

\section{Considerações finais}

Considera-se que Títulos e Resumos de artigos são relevantes como representativos na produção científica. Na mesma medida, são as escolhas de pesquisa, visto que revelam campos e suas tensões: área na qual se deseja investigar, propósitos do trabalho e caminhos metodológicos que possam levar à realização desses propósitos, dentre outras informações que o pesquisador é levado a construir mediante a simples elaboração de um projeto de pesquisa e consequente publicação.

Por meio das duas etapas realizadas para a efetivação deste artigo, a saber: a bibliometria (quantitativo das produções) e a metassíntese (análise qualitativa) dos títulos dos artigos (anos de 2010 a 2014) do periódico online Psicologia \& Sociedade acerca da categoria 'Trabalho', atingimos um ponto fundamental no incremento da pesquisa: a análise dos resumos, no intuito de transcender a síntese dos dados. Em consequência, cada etapa empreendida nesta pesquisa correspondeu a um retorno às fases anteriores, considerando a importância da tessitura de todo o estudo realizado. A chamada metassíntese foi ampliada e subdividida em mais duas partes: análise de resumos e análise de artigos. Para tanto, a apropriação das produções por nós, pesquisadoras, foi essencial.

A análise dos resumos, a qual recebeu da fase anterior, análise dos títulos, o quantitativo de 15 publicações, resultou em 12 artigos, a maioria classificada como pesquisas de campo. A etapa subsequente recebeu um recorte especial, quando foram apreendidos dois artigos, publicados em 2013, para serem analisados na íntegra.

A seleção de tais artigos ocorreu pelo fato de se tratarem de pesquisas teóricas, para então compreendermos essas construções sobre a categoria 'Trabalho' e seu diálogo com a psicologia, a partir de diferentes perspectivas, que, em dado momento, aproximam-se e, em outro, são contrastadas. Concluímos que, do ponto de vista dos avanços científicos da Psicologia do Trabalho, os artigos analisados não aportaram a categoria 'Trabalho' em relação com a subjetividade, eixo de pesquisa em constante expansão, ainda que o Artigo B tenha apresentado pequeno indício desta ligação.

Segundo Borges (2010), o florescimento do campo do saber da Psicologia do Trabalho e das Organizações, no Brasil, pode ser dimensionado a começar dos marcos históricos atuais, a exemplo da criação de espaços instituídos para discussão, como revistas científicas especializadas, congressos e associações; assim como pela multiplicação das linhas de pesquisa nos cursos de pós-graduação stricto senso e pelo aumento do número de pesquisadores que promovem discussões sobre o 'Trabalho', para além do materialismo dialético e das questões capitalistas, o que representa um amadurecimento gradual deste campo do conhecimento na atualidade.

Desta forma, compreendemos o quanto é vasto o campo da Psicologia do Trabalho, como também, a 
gama de teorias que o permeiam. Ademais, reiteramos a importância da pesquisa com o banco de dados online da Psicologia \& Sociedade, o qual dispõe de uma proposta desafiadora, fomentando interlocuções entre a Ciência Psicológica e a realidade social.

Evidenciamos a importância do exercício do diálogo contínuo com as mais diversas áreas do conhecimento, corroborando com a ideia de que o humano é um ser multifacetado, construído e construtor de sua complexidade. Assim, contribui-se para a qualificação e consolidação deste campo de conhecimento, histórica e culturalmente marcado por tantas descontinuidades.

Consideramos, ao longo da pesquisa, o índice significativo de publicações da Revista, que abordaram a categoria 'Trabalho', e de como a psicologia e áreas afins têm se debruçado na construção de caminhos teórico-metodológicos diversos para apreender as dimensões que perpassam tal categoria de análise. Neste sentido, o presente estudo descritivoexploratório culminou numa produção que não se esgota em si mesma, subsidiando novas possibilidades de investigações, especialmente análise de métodos utilizados em artigos de pesquisas de campo, enriquecendo e referendando os avanços científicos da Psicologia do Trabalho no Brasil.

\section{Referências}

Afonso, M. L. M., Hennon, C. B., Carico, T. L., \& Peterson, G. W. (2013). Uma abordagem metodológica para trabalhar com famílias no SUAS: uma leitura crítica através das lentes da cidadania. Psicologia \& Sociedade, 25(n. spe.), 80-90. Acesso em 16 de maio, 2016, em http://www.scielo.br/scielo. php?script $=$ sci arttext\&pid $=$ S0102-71822013000500010

Araújo, C. A (2006). Bibliometria: evolução histórica e questões atuais. Revista em Questão, 1(12), 11-32. Acesso em 16 de maio, 2016, em http://www.revistas.univerciencia.org/index. php/revistaemquestao/article/viewFile/3707/3495

Barros, M. E. B., Passos, E., \& Eirado, A. (2014). Psicologia e trabalho docente: intercessões com a clínica da atividade. Psicologia \& Sociedade, 26(n. spe.), 150- 160. Acesso em 16 de maio, 2016, em http://www.scielo.br/scielo. php?script=sci_arttext\&pid=S0102-71822014000500016

Batista, M. K., Grisci, C. L. I., Gallon, S., \& Figueiredo, M. D. (2013). Slow Movement: trabalho e experimentação do tempo na vida líquido-moderna. Psicologia \& Sociedade, 25(1), 30-39. Acesso em 16 de maio, 2016, em http:// www.scielo.br/scielo.php?script $=$ sci arttext\&pid $=\mathrm{S} 0102-71822013000100005$

Borges, L. O. (2010). A psicologia do trabalho e das organizações no Brasil floresce? Estudos de Psicologia, 15(3), 277-279. Acesso em 19 de julho, 2016, em http://www.scielo.br/pdf/ epsic/v15n3/a07v15n3

Carvalho, V. D., Villas Boas, E. M., Guerra, A. C., \& Freitas, T. A. (2014). Valores do trabalho e incubação de empreendimentos solidários: a experiência da Associação Terra do Marolo.
Psicologia \& Sociedade, 26(2), 449- 460. Acesso em 16 de maio, 2016, em http://www.ufrgs.br/seerpsicsoc/ojs2/index. php/seerpsicsoc/article/view/3765

Cockell, F. F. (2014). Idosos aposentados no mercado de trabalho informal: trajetórias ocupacionais na construção civil. Psicologia \& Sociedade, 26(2), 461-471. Acesso em 16 de maio, 2016, em http://www.ufrgs.br/seerpsicsoc/ojs2/ index.php/seerpsicsoc/article/view/3766

Coelho, C. M., Sampaio, R. F., \& Mancini, M. C. (2014). Trabalhadores com deficiência: vivências de prazer e sofrimento. Psicologia \& Sociedade, 26(1), 214-223. Acesso em 16 de maio, 2016, em http://www.scielo.br/scielo. php?script $=$ sci arttext\&pid $=$ S0102-71822014000100023

Dejours, C. (1987). A loucura do trabalho: estudo de psicopatologia do trabalho. São Paulo: Cortez.

Demo, P. (1994). Pesquisa e construção do conhecimento: metodologia científica no caminho de Habermas. Rio de Janeiro: Tempo Brasileiro.

Dias, B. C. C., Cherfên, V. P. R. F., Raupp, L. M., \& MilnitiskySapiro, C. (2014). Representações sociais de papeleiros acerca do trabalho e moradia: o caso da Vila Chocolatão. Psicologia \& Sociedade, 26(n. spe.), 193-200. Acesso em 16 de maio, 2016, em http://www.ufrgs.br/seerpsicsoc/ojs2/ index.php/seerpsicsoc/article/view/3737

Dutra-Thomé, L., Alencastro, L. S., \& Koller, S. H. (2014). A narrativa como proposta metodológica para o estudo do Burnout. Psicologia \& Sociedade, 26(n. spe.), 107-116. Acesso em 16 de maio, 2016, em http://www.ufrgs.br/ seerpsicsoc/ojs2/index.php/seerpsicsoc/article/view/3729

Furlan, R. (2008). A questão do método na Psicologia. Psicologia em Estudo, 13(1), 25-33. Acesso em 16 de maio, 2016, em http://www.scielo.br/scielo.php?pid=S1413$73722008000100004 \&$ script $=$ sci abstract $\&$ tlng $=$ pt

Gomes, A. R., Montenegro, N., Peixoto, A. M. B. C., \& Peixoto, A. R. B. C. (2010). Stress ocupacional no ensino: um estudo com professores dos $3^{\circ}$ ciclo e ensino secundário. Psicologia \& Sociedade, 22(3), 587-597. Acesso em 16 de maio, 2016, em http://www.scielo.br/scielo.php?pid=S0102$71822010000300019 \&$ script $=$ sci abstract\&tlng $=$ pt

Gonçalves, R. M. P. \& Jimenez, S. V. (2013). Relações antagônicas entre sentido e significado do trabalho no capital: uma análise na perspectiva ontológica. Psicologia

\& Sociedade, 25(3), 685-694. Acesso em 16 de maio, 2016, em http://www.scielo.br/scielo.php?script=sci arttext\&pid $=\mathrm{S} 0102-71822013000300022$

Matheus, M. C. C. (2009). Metassíntese qualitativa: desenvolvimento e contribuições para a prática baseada em evidências. Acta Paulista de Enfermagem, 22(n. spe.), 543545. Acesso em 16 de maio, 2016, em http://www.scielo.br/ scielo.php?pid $=$ S0103-21002009000800019\&script $=$ sci abstract\&tlng $=\mathrm{pt}$

Raitz, T. R. \& Silva, C. D. L. (2014). Trajetórias identitárias e sentidos do trabalho docente para professores universitários. Psicologia \& Sociedade, 26(1), 204-213. Acesso em 16 de maio, 2016, em http://www.ufrgs.br/seerpsicsoc/ojs2/index. php/seerpsicsoc/article/view/3708/2324

Rocha, N. M. F. D. \& Góis, C. W. L. (2010). Trajetórias de jovens no mundo do trabalho a partir da primeira inserção: o caso de Sísifo em Maracanaú - Ceará, Brasil. Psicologia \& Sociedade, 22(3), 466-475. Acesso em 16 de maio, 2016, em http://www.scielo.br/scielo.php?script=sci arttext\&pid $=\mathrm{S} 0102-71822010000300007$ 
Santos, D. P., Alberto, M. F. P., Costa, R. R., \& Santos, C. B. (2013). Implicações do trabalho precoce para adultos: vivências e infância. Psicologia \& Sociedade, 25(n. spe.), 91-100. Acesso em 16 de maio, 2016, em http://www.scielo.br/scielo.php?script=sci_arttext\&pid $=\mathrm{S} 0102-71822013000500011$

Sato, L., Lacaz, F. A., \& Bernardo, M. H. (2006). Psicologia e saúde do trabalhador: práticas e investigações na Saúde Pública de São Paulo. Estudos de Psicologia, 11(3), 281288. Acesso em 19 de julho, em

http://www.scielo.br/scielo.php?script=sci arttext\&pid=S1413-294X2006000300005>

Schlindwein, V. L. D. C. (2013). Histórias de vida marcadas por humilhação, assédio moral e adoecimento no trabalho. Psicologia \& Sociedade, 25(2), 430-439. Acesso em 16 de maio, 2016, em http://www.ufrgs.br/seerpsicsoc/ojs2/index. php/seerpsicsoc/article/view/3597

Silva, M. S. \& Barros, V. A. (2014). Saberes sobre o trabalho: experiência e história nos canaviais. Psicologia \& Sociedade, 26(2), 440-448. Acesso em 16 de maio, 2016, em http://www.ufrgs.br/seerpsicsoc/ojs2/index.php/seerpsicsoc/ article/view/3764

Trancoso, E. A. R. (2012). Juventudes: o conceito na produção científica brasileira. Dissertação de Mestrado, Programa de Pós-graduação em Psicologia, Universidade Federal de Alagoas, Maceió.
Submissão em: 12/05/2016

Revisão em: 18/07/2016

Aceite em: 25/07/2016

Adélia Augusta Souto de Oliveira é professora associada da Universidade Federal de Alagoas. Diretora do Instituto de Psicologia. Docente permanente do Programa de Pós-graduação Stricto Sensu em Psicologia na mesma universidade. Doutora em Psicologia Social pela Pontifícia Universidade Católica de São Paulo e pós-doutoranda em Psicologia Social pela Universidad de Barcelona. Integrante do GT da ANPEPP: A Psicologia sócio-histórica no contexto de desigualdade social brasileiro.

Endereço: Campus A.C. Simões, Instituto de Psicologia, Av. Lourival Melo Mota, s/n, Tabuleiro dos Martins. CEP 57072-900. Maceió, AL, Brasil.

E-mail: adeliasouto@ip.ufal.br

Cristina Generino dos Santos Lima é graduanda em Psicologia, Universidade Federal de Alagoas.

E-mail: cristinapsiufal@hotmail.com

Kalina Karla Clemente de Morais é graduanda em Psicologia, Universidade Federal de Alagoas.

E-mail: kalina.psicologia@gmail.com 